\title{
The Cholinergic System Modulates Memory and Hippocampal Plasticity via Its Interactions with Non-Neuronal Cells
}

\author{
Sara V. Maurer* and Christina L. Williams* \\ Department of Psychology and Neuroscience, Duke University, Durham, NC, United States
}

OPEN ACCESS

Edited by:

Valentin A. Pavlov,

Northwell Health, United States

Reviewed by:

Alessandro Martorana,

Università degli Studi di Roma

Tor Vergata, Italy

Maryna Skok,

Palladin Institute of Biochemistry

(NAN Ukraine), Ukraine

Donald B. Hoover,

East Tennessee State University,

United States

Dimitrios Davalos,

Cleveland Clinic Lerner College

of Medicine, United States

*Correspondence:

Sara V. Maurer

svm8@duke.edu:

Christina L. Williams cwilli@duke.edu

Specialty section: This article was submitted to Inflammation,

a section of the journal

Frontiers in Immunology

Received: 01 August 2017

Accepted: 23 October 2017

Published: 08 November 2017

Citation:

Maurer SV and Williams CL (2017) The Cholinergic System Modulates

Memory and Hippocampal

Plasticity via Its Interactions with

Non-Neuronal Cells.

Front. Immunol. 8:1489.

doi: 10.3389/fimmu.2017.01489
Degeneration of central cholinergic neurons impairs memory, and enhancement of cholinergic synapses improves cognitive processes. Cholinergic signaling is also anti-inflammatory, and neuroinflammation is increasingly linked to adverse memory, especially in Alzheimer's disease. Much of the evidence surrounding cholinergic impacts on the neuroimmune system focuses on the $\alpha 7$ nicotinic acetylcholine (ACh) receptor, as stimulation of this receptor prevents many of the effects of immune activation. Microglia and astrocytes both express this receptor, so it is possible that some cholinergic effects may be via these non-neuronal cells. Though the presence of microglia is required for memory, overactivated microglia due to an immune challenge overproduce inflammatory cytokines, which is adverse for memory. Blocking these exaggerated effects, specifically by decreasing the release of tumor necrosis factor $\alpha(\mathrm{TNF}-\alpha)$, interleukin $1 \beta(\mathrm{IL}-1 \beta)$, and interleukin $6(\mathrm{IL}-6)$, has been shown to prevent inflammation-induced memory impairment. While there is considerable evidence that cholinergic signaling improves memory, fewer studies have linked the "cholinergic anti-inflammatory pathway" to memory processes. This review will summarize the current understanding of the cholinergic anti-inflammatory pathway as it relates to memory and will argue that one mechanism by which the cholinergic system modulates hippocampal memory processes is its influence on neuroimmune function via the $\alpha 7$ nicotinic ACh receptor.

\footnotetext{
Keywords: alpha 7 nicotinic acetylcholine receptor, hippocampal memory, microglia, cholinergic anti-inflammatory pathway, neuroinflammation
}

\section{INTRODUCTION}

Cholinergic circuits have been implicated in normal and abnormal cognitive functioning since 1906, when Dr. Aloysius Alzheimer described the symptomatology and neuropathology of the disease that today bears his name (1). Disruption of cholinergic circuitry is likely to be at least partly responsible for the cognitive impairments seen in neurodegenerative disorders $(2,3)$. Recent studies have also revealed deficits in cholinergic signaling in disorders of attention and cognitive control [see Ballinger et al. (4)]. While the mechanism by which cholinergic signaling influences cognitive processes has been assumed to be direct cholinergic stimulation of pre- and postsynaptic neuronal receptors, a neglected area of investigation is the role of acetylcholine's (ACh) peripheral and central anti-inflammatory effects on cognition. Neuroinflammation is also a hallmark 
of neurodegenerative disorders and has been implicated in the neuropathogenesis of Alzheimer's disease (AD). Not only do neurons respond directly to ACh but also do non-neuronal cells: peripheral macrophages, as well as microglia and astrocytes in the central nervous system (CNS). These non-neuronal cells influence short-term and long-term synaptic function and plasticity [reviewed in Achour and Pascual (5)], and through these mechanisms may contribute to both dysfunction and improvements in cognition.

Though certainly not the only mechanism, this review posits that ACh may influence hippocampal function via peripheral and central immune cells, and through this intermediary process, may alter neuronal processes underlying cognition (6). First, this review will describe the intercellular components and pathways of the cholinergic system relevant to memory, with a special focus on the effects of ACh in the hippocampus. Second, this review will explore the role of ACh in hippocampal memory and plasticity, examining both the direct and indirect roles that ACh may have in modulating hippocampal function. A final section of the review will highlight how cholinergic modulation of the immune system may provide new perspectives on regulating memory dysfunction in disease.

\section{THE CHOLINERGIC SYSTEM}

\section{Synthesis and Synapses}

Acetylcholine was first identified by Dale (7) for its actions on heart tissue. It was later recognized as a neurotransmitter by Loewi (8), who initially named it "Vagusstoff" because it was released from the vagus nerve. Since then, the intricate workings of ACh synthesis and synaptic communication have been identified.

Cholinergic synthesis and reuptake in neurons is well understood. First, ACh is synthesized from choline and acetyl-CoA via the choline acetyltransferase (ChAT) enzyme. ACh is subsequently transported into vesicles and released into the synaptic cleft, where it can bind to the muscarinic and/or nicotinic ACh receptors. Within the synapse, ACh is broken back down into choline and acetic acid by acetylcholinesterase (AChE). Choline reuptake occurs via a high affinity choline transporter, and then choline is recycled in the synthesis of new ACh.

However, neurons are not the only cells to synthesize ACh: cells from the skin, kidney, eye, liver, and placenta all contain ChAT (9). T-cells also show ChAT activity, synthesize ACh, and have been shown to "relay the neural signal" in the cholinergic anti-inflammatory pathway by releasing $\mathrm{ACh}$, which subsequently acts on macrophages via the $\alpha 7$ nicotinic ACh receptor (10). ChAT activity has also been found in non-neuronal cells in the CNS, specifically in astrocytes (11). At this time, it is not clear whether microglia show any ChAT activity (12). Further work is needed to pinpoint the cell types involved in ACh synthesis and how they act upon and with neuronal ACh.

\section{Receptors}

There are two kinds of ACh receptors: nicotinic (nAChR) and muscarinic (mAChR). nAChRs, which will be a focus of this review, are ligand-gated ion channels and occur in the neuromuscular junction, autonomic ganglia, and throughout the CNS. One specific subtype of nAChR identified to be functionally important in hippocampal memory [though not the only one; see Chan et al. (13)] is the $\alpha 7 \mathrm{nAChR}$.

Using various agonists and antagonists such as nicotine and $\alpha$-bungarotoxin, $\mathrm{nAChRs}$ have been extensively mapped in the rodent brain (14), and, to a lesser extent, the human brain (15). Notably, the hippocampus has almost every nAChR subtype (16), has a high density of $\alpha 7 \mathrm{nAChR}$ receptors, and expresses cholinergic receptors both pre- and post-synaptically (17). The distribution of receptors is highly preserved across species and is similar in both rodent and human brains (15).

As reviewed in Albuquerque et al. (6), nAChRs are also present in non-neuronal cells, including keratinocytes, endothelial cells, cells in the digestive, respiratory, and peripheral immune systems, and-critically-on glia (18-20). In the brain, both microglia (21, 22 ) and astrocytes (23) express $\alpha 7$ nAChRs $(22,24)$.

Alpha-bungarotoxin, which is a specific antagonist to $\alpha 7$ and $\alpha 9 \mathrm{nAChRs}$, was used to show the dense $\mathrm{nAChR}$ population on human macrophage surfaces (25). Additionally, administration of nicotine decreased $\alpha$-bungarotoxin binding, further providing support for the specificity of this marker. RT-PCR, western blotting, $\alpha$-bungarotoxin-conjugated beads, and cloning of cDNA showed definitively that the $\alpha 7 \mathrm{nAChR}$ was specifically responsible for this binding (25).

\section{Circuits}

In the CNS, cholinergic neurons reside in three major areas: (1) there are cholinergic neurons in the brainstem, where they may function in risk aversion (26). The cholinergic neurons in this area project to and inhibit the thalamus $(27,28)$. (2) There are cholinergic interneurons in the striatum, which suppress dopamine release (29). (3) There are cholinergic neurons that originate in the basal forebrain, mainly in the medial septum, vertical limb of the diagonal band (MS/VDB), horizontal limbs of the diagonal band, and nucleus basalis. These cells project to the olfactory bulb, neocortex, hippocampus, and amygdala (30-32). Cholinergic neurons in the MS/VDB project to all of the subregions of the hippocampus $(33,34)$. There are also cholinergic interneurons in the cortex itself, but they are scarce (35). Basal forebrain neurons, specifically those in the nucleus basalis, selectively degenerate in $\mathrm{AD}$ (36) and have been a focus of research on the relation between ACh and memory.

There are also projections from the basal forebrain to the frontal cortex, which are involved in attentional processes (37). Attention is known to have a beneficial role in memory itself. Though the interaction of attention and memory is beyond the scope of this review, it is important to note that both functions rely on cholinergic projections from the basal forebrain, so experiments manipulating these connections could be impacting both memory and attention.

Interestingly, few of the recent reviews (38-42) of ACh actions in the CNS mention that many non-neuronal cells in the body and brain manufacture and respond to ACh. As well, few acknowledge that peripheral ACh actions may impact CNS function. These findings are reviewed below. 


\section{ACh in the Periphery}

Acetylcholine is the neurotransmitter in all preganglionic neurons in both the sympathetic and parasympathetic nervous systems, as well as all parasympathetic postganglionic neurons. However, only a small number of sympathetic postganglionic neurons are cholinergic (those innervating sweat glands) whereas the rest are adrenergic. Within the somatic nervous system, all motor neurons that innervate skeletal muscles are cholinergic.

\section{The Cholinergic Anti-inflammatory Pathway}

The finding that activation of the efferent vagus nerve inhibits proinflammatory cytokine release and protects against peripheral inflammation led to this connection between $\mathrm{ACh}$ and inflammation to be named "the cholinergic anti-inflammatory pathway" [(43); see Figure 1]. Stimulation of the vagus nerve, either endogenously or through electrical stimulation, leads to increased ACh release (synthesized from T-cells), which acts on macrophage $\alpha 7$ nAChRs. This activation leads to a decreased production of inflammatory cytokines, such as tumor necrosis factor $\alpha$ (TNF- $\alpha$ ), interleukin $1 \beta$ (IL-1 $\beta$ ), and interleukin 6 (IL-6), by macrophages [reviewed in Gallowitsch-Puerta and Pavlov (44)]. Peripheral ACh also acts on $\alpha 7 \mathrm{nAChRs}$ on lymphocytes to suppress inflammation $(20,45-47)$. ACh also produces a dosedependent inhibition of IL- 6 , IL- $1 \beta$, and TNF- $\alpha$ production in human macrophages [reviewed in Pavlov and Tracey (43) and Borovikova et al. (48)] and in whole-blood of rheumatoid arthritis

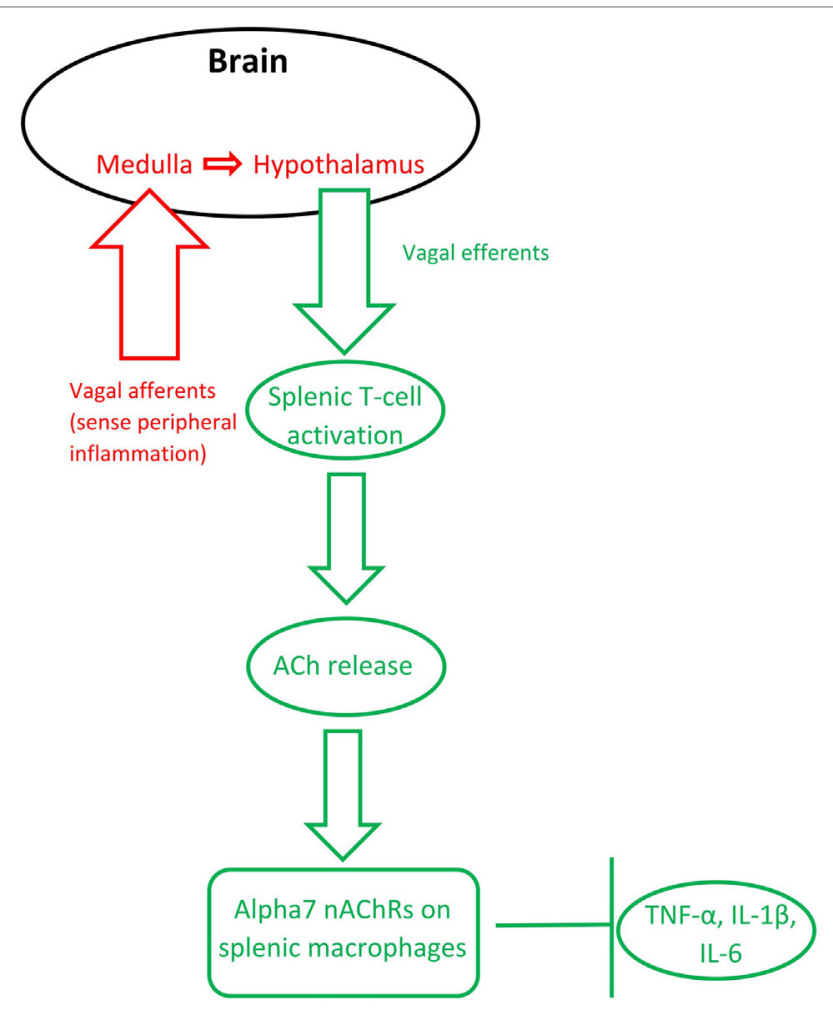

FIGURE 1 | The inflammatory reflex (red) and the cholinergic antiinflammatory pathway (green). Based on Steinberg et al. (50) and Gallowitsch-Puerta and Pavlov (44). patients (49), whereas vagotomy leads to increases in IL-6 and, to a lesser extent, TNF- $\alpha$ (48).

Importantly, the vagus nerve's anti-inflammatory action is also bidirectional: the afferent vagus nerve detects peripheral cytokines, then communicates through the medulla to the hypothalamus, which subsequently communicates via the efferent vagus nerve to inhibit inflammation in the periphery (51). In other words, the bidirectional anti-inflammatory communication between the brain and periphery relies on the vagus nerve and ACh signaling. Termed the "inflammatory reflex," the afferent vagus immediately regulates production of pro-inflammatory cytokines to avoid overproduction (52).

The cholinergic anti-inflammatory pathway relies on activation of $\alpha 7 \mathrm{nAChRs}$ on macrophages. Alpha7 nAChR stimulation has been shown to modulate TNF- $\alpha$ release (53). AChE inhibitor administration, which decreases the breakdown of ACh, leads to lower levels of IL- 6 and TNF- $\alpha$, but does not significantly alter cytokine release in $\alpha 7 \mathrm{nAChR}$ knockout mice (54). Macrophages stimulated with the bacterial mimic lipopolysaccharide (LPS) produce more TNF- $\alpha$, which is blunted by nicotine pretreatment; however, additional pretreatment with an antisense oligonucleotide for $\alpha 7 \mathrm{nAChRs}$ (but not $\alpha 1$ or $\alpha 10 \mathrm{nAChRs}$ ) ameliorated this effect (25). These findings specifically implicate the $\alpha 7 \mathrm{nAChR}$, a receptor otherwise known to be important for hippocampal memory, in the cholinergic anti-inflammatory pathway.

Like peripheral macrophages, microglia have $\alpha 7$ nAChRs, which, when activated, suppress pro-inflammatory cytokine release $(53,55)$. In mouse and human cell culture studies, it has been shown that $\alpha 7 \mathrm{nAChRs}$ on microglia are necessary for blunting TNF- $\alpha$ and downstream IL- $1 \beta$ production $(55,56)$. AChE inhibitors have been shown to suppress TNF- $\alpha$ secretion from microglia, and addition of $\alpha$-bungarotoxin blunted these effects (57). Peripheral macrophages and microglia-the macrophages of the brain-seem to respond similarly to ACh.

Thus far, this review has summarized evidence that ACh is synthesized by neurons but also by non-neuronal cells. Basal forebrain cholinergic neurons release $\mathrm{ACh}$ in all regions of the hippocampus, which all contain nAChRs. The hippocampus in particular is a region with a high density of microglia and astrocytes (58) as well as a high density of nAChRs. These findings suggest that cholinergic stimulation of the hippocampus not only has direct neuronal effects but also effects on microglia and astrocytes that may modulate neuronal function.

\section{MEMORY AND NEURAL PLASTICITY}

\section{The Classic View of the Cholinergic System in Memory}

Recent reviews of basal forebrain cholinergic systems in memory and cognition $(4,59-62)$ focus on the septohippocampal pathway, which is widely known to be implicated in memory processes. Below, the standard view of septohippocampal ACh functions in memory are reviewed, followed by a proposal for some alternate means by which ACh may have effects on hippocampal memory.

There are a number of lines of evidence that support the view that hippocampal ACh is important for memory [see Parent and 
Baxter (63)]. First, during spatial memory tasks, cholinergic markers such as ChAT are upregulated [see Park et al. (64)]. Second, ACh levels in the hippocampus are correlated with memory function. For example, there is a correlation between age-related cognitive decline and decreases in hippocampal ACh (65). Multiple studies find a correlation between spatial memory and ACh release both in the hippocampus (66), and within the basal forebrain (67). Also, damage to the septum leads to decreases in both spatial memory performance and hippocampal levels of ACh (68). Function can be rescued when basal forebrain AChE is inhibited pharmacologically. Third, both the direct infusion of ACh into the hippocampus and direct pharmacological activation of nAChRs in the hippocampus reverse the cognitive deficits caused by damage to the septum (69-72). Importantly, this finding shows that while the basal forebrain provides multiple inputs to the hippocampus, direct activation of nAChRs in the hippocampus reverses cognitive dysfunction caused by interruption of this pathway. While all of these data have traditionally been interpreted as direct actions of ACh on neuronal receptors, hippocampal astrocytes (18) and microglia (53) also express nAChRs. Therefore, all of these findings leave open the possibility that some of the actions of ACh on the hippocampus may be via nicotinic activation of glial cells. However, more research to tease apart the direct neuronal and indirect non-neuronal actions of ACh in memory is needed.

\section{ACh is the "Decider" between Encoding and Retrieval}

The classically held view is that ACh is the decider between encoding mode and retrieval mode in memory processing (73, 74). ACh is associated with suppressing old associations and inhibiting proactive interference. Rats with cholinergic basal forebrain lesions perform comparably to controls in a water maze task unless the location of the platform changed daily (75). An explanation for this finding is that the lack of ACh in the hippocampus leads to more expression of a previously encoded association (which would be the previous location of the platform). However, rats with intact cholinergic systems are able to inhibit the previous association, and form a new one. Hasselmo (74) in addition to Easton et al. (73) provided extensive reviews describing what may be the neural underpinnings of this phenomenon. Briefly, the CA1 region of the hippocampus receives input from two brain regions: entorhinal cortex layer 3 (associated with sensory perception- "extrinsic input") and the CA3 region of the hippocampus (associated with previously formed associations"intrinsic input"). ACh reduces the relative input from CA3, hence allowing sensory inputs to be encoded, free from proactive inhibition. In this way, hippocampal ACh "prioritizes encoding" in novel contexts. This extended model implicates hippocampal ACh directly in the encoding phase and also allows working memory to be more efficient.

Further support for this hypothesis mostly relies on hippocampal ACh and its association with increased exploratory behavior. Evidence shows that hippocampal ACh levels are increased in instances of novelty (76) and exploratory rearing (77) compared to non-novel environments. The authors conclude from this work that the state of novelty itself activates the cholinergic system. Frontal cortical and dorsal hippocampal ACh, glutamate, and GABA measured through microdialysis in response to exploration of a novel environment support this interpretation (76). In both brain areas, but exaggerated in the hippocampus, ACh was significantly increased during the first session of exploration. Additionally, infusion of ACh agonists into the hippocampus led to increased exploratory behavior (78). The take-away from these studies is that increased hippocampal ACh release, caused by a novel environment, aids encoding and increases exploratory behavior. While this evidence points to hippocampal ACh as an indicator and facilitator of encoding in novel contexts, it does not address the contribution of other cells that ACh may stimulate.

\section{Non-Neuronal Actions of the Cholinergic System in Memory}

Recent work has, in fact, demonstrated that ACh acts directly on hippocampal astrocytes, which then leads to alterations in firing of hippocampal neurons (79). Consistent with Hasselmo's view (80) that high levels of ACh aid encoding by suppressing inappropriate activations, specific optogenetic stimulation of septal cholinergic neurons led to decreased firing of dentate granule cells. Administration of an $\alpha 7 \mathrm{nAChR}$ antagonist blocked this effect, indicating that this receptor is responsible for the decreased firing. The critical aspect of the findings, however, is that disrupting astrocytic function in the hilar layer of the hippocampus by an inhibitor of glial metabolism prevented inhibition of dentate granule cells caused by septal cholinergic stimulation. These findings revealed that septohippocampal release of ACh causes a slow inhibition of dentate granule cells, not by acting directly on neurons but rather by activating astrocytes (see Figure 2). As well, it was found that a $\mathrm{AChR}$ antagonist prevented activation of astrocytes, indicating that astrocytes are specifically responding to basal forebrain cholinergic inputs through this class of receptor, specifically the $\alpha 7 \mathrm{nAChR}$. When activated, astrocytes can release neurotransmitters like glutamate $(81,82)$ and consequently suppress activation of dentate granule cells via hilar inhibitory interneurons. As further support for the view that hippocampal astrocytes play a role in hippocampal function, blocking transmitter release from astrocytes impaired hippocampal-dependent novel object recognition memory, but not all types of memory (83). These data provide support for the view that basal forebrain ACh release may influence hippocampus and memory via slow inhibition of neuronal activity via astrocyte intermediaries.

In addition to astrocytes, microglia are necessary for hippocampal memory and motor-learning dependent synapse formation, likely via microglial brain-derived neurotrophic factor (BDNF) (84). To address whether or not microglia are necessary for memory, mice expressing tamoxifen-inducible Cre recombinase that allowed for specific manipulation of gene function in microglia were generated. Then, Cre was used to induce diphtheria toxin receptor expression solely in microglia. Mice depleted of microglia via diphtheria toxin administration showed deficits in hippocampal-dependent fear conditioning and novel objectmemory tasks, indicating that microglia are critical for emotional and hippocampal-dependent memory (85). As well, depleting 


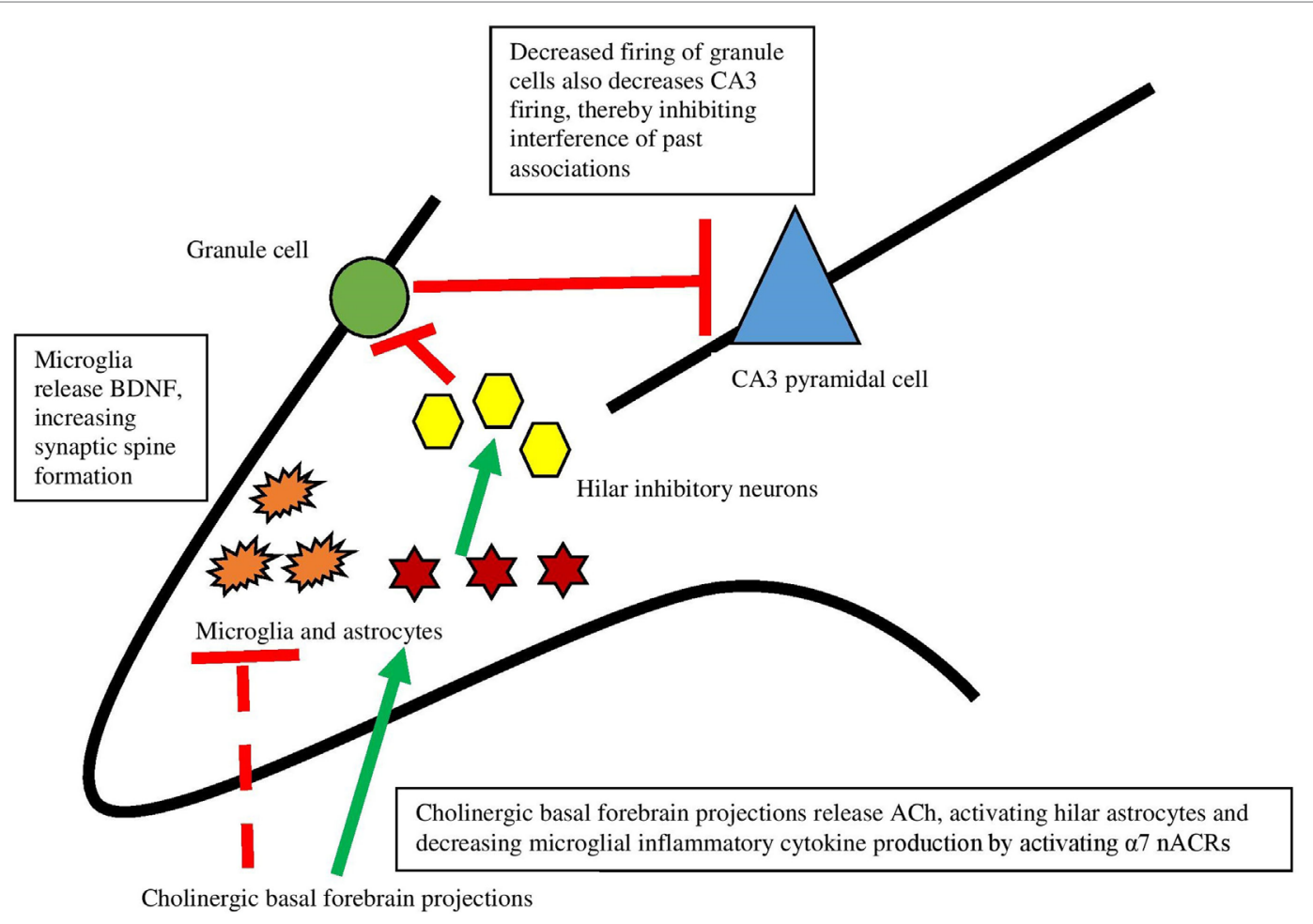

FIGURE 2 | The interaction between the cholinergic system and glia and its impact on the hippocampus. Dotted lines represent cytokine effects, and solid lines represent cell activation/firing. Cholinergic basal forebrain projections release ACh and both decrease cytokine release from microglia and activate hilar astrocytes. Those astrocytes activate inhibitory interneurons, which decreases firing from granule cells. This decreased firing leads to decreased firing of CA3 pyramidal cells, preventing interference of past associations in encoding. Based largely on Hasselmo (74) and Pabst et al. (79).

microglial BDNF mimicked the effects of microglial elimination on memory function and synaptic spine formation, suggesting a potential mechanism for the memory effects. Interestingly, there were no differences in the expression of TNF- $\alpha$, IL- $1 \beta$, and IL- 6 in microglial-depleted and control mice-possibly indicating a compensatory production mechanism (for example, production of cytokines by non-microglial cells like astrocytes, or cytokines entering the CNS through the blood-brain barrier). Regardless, the memory impairments were not due to the increase or decrease of these cytokines. Microglial depletion has also been shown to impair spatial memory in mice trained on a Barnes maze (86).

Though microglia are necessary for memory, overactivation of microglia, which causes increased release of proinflammatory cytokines (such as TNF- $\alpha$, IL- $1 \beta$, and IL-6), is detrimental. This has been demonstrated in several studies of postoperative cognitive dysfunction (POCD).

Postoperative cognitive dysfunction is a decline in memory and executive functions that occurs shortly following surgery in some patients and can persist for several months or more (87). Memory impairment also occurs following peripheral orthopedic surgery in mice $(88,89)$. This mouse model of POCD has revealed that surgery not only increases pro-inflammatory cytokines in the periphery but also upregulates inflammation in the brain (90). These effects are not due to anesthesia, as mice given anesthesia without surgery do not show this inflammatory profile (90). Macrophage-produced TNF- $\alpha$ appears to promote
POCD by altering the permeability of the blood-brain barrier, allowing increased macrophage infiltration to the hippocampus after orthopedic surgery (88): prevention of macrophageproduced TNF- $\alpha$ prevented the increased permeability of the blood-brain barrier, and subsequently also prevented the increased macrophage migration into the brain after surgery. Orthopedic surgery leads to increased IL- $1 \beta$ in the hippocampus and impaired hippocampal-dependent fear conditioning, while anti-TNF antibody administration inhibits this effect (90).

Interestingly, stimulation of $\alpha 7 \mathrm{nAChRs}$ prevents the macrophage migration and cognitive deficits seen after surgery, and administration of an $\alpha 7$ antagonist increased neuroinflammation and POCD $(88,89)$. Because one of the agonists, choline, does not easily cross the blood-brain barrier, the authors conclude that it must be acting on peripheral macrophages. The cholinergic antiinflammatory pathway takes effect both peripherally by acting on macrophages to decrease proinflammatory cytokine release, and centrally by decreasing hippocampal pro-inflammatory cytokines (89) and macrophage activation and migration. Both of these inflammatory metrics influence fear conditioning: surgery leads to impaired memory, but $\alpha 7$ agonists rescue this behavior. Alpha7 antagonists further impair memory after surgery. Notably, orthopedic surgery also decreases hippocampal BDNF and neurogenesis (91).

In a study examining the effect of minocycline administration and surgery on inflammation and memory in an aged-mouse 
model of POCD, minocycline (which decreases microglial activation, but may also have effects on neurons) administered prior to surgery not only decreases hippocampal levels of inflammatory cytokines TNF- $\alpha$, IL-1 $\beta$, and interferon- $\gamma$ but also rescues spatial memory deficits that occur following surgery (92). Previous findings showing that microglia have $\alpha 7 \mathrm{nAChRs}$ suggest that activation of the cholinergic anti-inflammatory pathway might have similar effects to treatment with minocycline. The authors suggest that microglia may "get stuck" in an activated state after an immune challenge, and the continued release of inflammatory cytokines might facilitate cognitive aging and the associated memory impairment.

There is considerable support for the important role of cytokines released from microglia in memory modulation. Administration of inflammatory cytokines (specifically, TNF- $\alpha$ and IL-1 $\beta$ ) causes deficits in spatial memory (93-95) and hippocampal-dependent fear conditioning [(96); for review, see Pugh et al. (97)]. Following infection, it appears that it is microglia, not neurons or astrocytes, in the hippocampus that are responsible for the increase in IL-1 $\beta$, which then leads to impaired memory (98). Blocking IL-1 $\beta$ release in the CNS prevents the memory impairment caused by overactivation of microglia (99). Importantly, the complete absence of IL-1 $\beta$ is detrimental to memory-indicating basal levels are necessary, but overexpression of the cytokine is harmful (98). Even in the absence of other inflammatory factors and insults, the increased expression of TNF- $\alpha$ led to decreased performance in memory tasks such as passive avoidance (100). Though there is much research on the impact of inflammation in memory, more work is needed on the integration of ACh and neuroimmune factors on hippocampal-dependent memory.

\section{Markers of Plasticity: Neuronal and Non-Neuronal Influences}

As described previously, basal forebrain cholinergic inputs to the hippocampus play an important role in cognitive function. Therefore, it is not surprising that there is considerable evidence that $\mathrm{ACh}$ receptors are involved in various aspects of neural plasticity: long-term potentiation (LTP), regulation of BDNF, and hippocampal neurogenesis.

\section{Long-term Potentiation}

Acetylcholine "biases the system" toward increased LTP, believed to be one of the cellular foundations of learning and memory, by decreasing the induction threshold required $(101,102)$. In addition, in an in vitro high ACh environment, stimulation that normally produces long-term depression produces LTP (103). The specific neuronal mechanisms underlying this effect have largely been identified. ACh, when it binds to a muscarinic ACh receptor, leads to a signaling cascade activating phospholipase-C, which has been shown to contribute to LTP (104). Additionally, impaired LTP has been linked to malfunctioning $\alpha 7 \mathrm{nAChRs}$ (105). A blockade of $\alpha 7 \mathrm{nAChRs}$ blunted LTP, and $\alpha 7 \mathrm{nAChR}$ knockout mice can similarly show decreased LTP (106). The cholinergic systems' impact on LTP has always been interpreted as a direct synaptic action, but it is also possible that ACh is acting on glial $\alpha 7 \mathrm{nAChRs,}$ though research to date has not demonstrated this conclusively.

Impairments in hippocampal LTP have been linked to microglial overactivation, and minocycline normalizes these impairments (107). Clearly, microglia have an important role in LTP that has not been explored fully, and this role is possibly mediated by microglial $\alpha 7$ nAChRs.

Pharmacological activation of $\alpha 7 \mathrm{nAChRs}$ leads to increases in hippocampal LTP, quantified by long-lasting increases in calcium activity in the CA1 and CA3 regions of the hippocampus in wild-type, but not $\alpha 7$ nAChR knockout mice (108). Because the $\alpha 7 \mathrm{nAChR}$ is highly permeable to calcium, this specific receptor is likely causal for this effect (109). These data support the view that $\alpha 7 \mathrm{nAChR}$ activation on neurons as well as on microglia both aid LTP.

The effect of $\alpha 7 \mathrm{nAChR}$ activation is usually the decreased release of inflammatory cytokines, and these molecules have also been shown to impact LTP. TNF- $\alpha$ directly modulates the strength of synapses by altering postsynaptic AMPA receptor expression (110), leading to weakened synaptic strength and increased likelihood for that synapse to be engulfed by activated microglia. A proposed mechanism that may explain cognitive dysfunction in patients with immune disorders is suppression of the cholinergic anti-inflammatory pathway leading to heightened secretion of TNF- $\alpha$, altering astrocyte-neuron signaling, leading to a cascade resulting in a restructuring of the excitability of hippocampal synapses (111).

During LTP and hippocampal memory tasks, hippocampal IL- $1 \beta$ is released, and blocking IL- 1 receptors has an adverse effect on both memory and LTP $(98,112)$. So, though IL- $1 \beta$ is required for LTP, overexpression-such as that seen in pathological conditions-inhibits LTP (113). In other words, the effects of IL-1 $\beta$ on LTP follow the same "U-shaped" concentration-response curve as the effects of IL-1 $\beta$ in memory: moderate levels are necessary, but overexpression is detrimental. Because ACh inhibits release of inflammatory cytokines, perhaps the impact of ACh on LTP occurs via both direct neuronal and indirect non-neuronal action.

\section{Brain-Derived Neurotrophic Factor}

Acetylcholine has been shown to modulate plasticity via BDNF. Following chronic nicotine exposure (which activates nAChRs), BDNF in the hippocampus is upregulated $(114,115)$. Conversely, after loss of basal forebrain cholinergic neurons, hippocampal BDNF subsequently decreases (116). These data have been interpreted as a direct effect of $\mathrm{ACh}$ on neurons and this view is supported by the finding that in cultures of cortical neurons, $\alpha 7 \mathrm{nAChR}$ stimulation produces dose-dependent increases in BDNF. However, there is also evidence that microglia modulate BDNF release. For example, hippocampal microglial activation following LPS administration led to decreased BDNF in the CA1 region of the hippocampus (117). Two studies by Ruth Barrientos and colleagues show that hippocampal IL- $1 \beta$, likely produced by microglia, regulates BDNF. In one study, social isolation stress lowered BDNF levels in the hippocampus of mice, but levels were restored when an IL-1 receptor antagonist was administered to the hippocampus (118). In a second study, the increase of hippocampal BDNF following context learning was blocked by 
administering IL-1 $\beta$ to the hippocampus (119). High levels of IL-6 also suppress BDNF (120). There is at least some evidence that ACh modulation of inflammation can alter BDNF release. Vagal nerve stimulation, known to release ACh in the periphery and to be a catalyst for the cholinergic anti-inflammatory pathway, has been shown to upregulate both neurogenesis and BDNF in the hippocampus after 24 hours and 3 weeks of treatment (121). Though the mechanism of this effect is not yet known, it may be because vagal stimulation also enhances serotonin (via the raphe nucleus) and norepinephrine (via the locus ceruleus) in the CNS [see Biggio et al. (121)]. This increase in norepinephrine could lead to increased cholinergic signaling in the basal forebrain (122), contributing to increased hippocampal neurogenesis (123). Peripheral cholinergic stimulation (89) and vagal nerve stimulation (124) are also known to decrease neuroinflammation, which contributes to increased hippocampal neurogenesis (125).

Importantly, the effects of BDNF and activation of $\alpha 7$ nAChRs appear to be reciprocal. BDNF increases the density of $\alpha 7 \mathrm{nAChRs}$ on hippocampal neurons (126), and activation of $\alpha 7 \mathrm{nAChRs}$ leads to upregulated BDNF in the hippocampus (127). Together, these data suggest that the cholinergic system modulates BDNF and neural plasticity via both direct neuronal and indirect glial actions.

\section{Neurogenesis}

The dentate gyrus (DG) of the hippocampus is one of the most plastic regions in the mammalian brain because it is able to generate principal neurons that integrate into the pre-existing network throughout life. Moreover, basal forebrain cholinergic projections to the DG have been shown to facilitate neurogenesis (128-130). Enhanced adult hippocampal neurogenesis improves pattern separation ability, temporal separation of events in memory, forgetting, and cognitive flexibility [see recent review: Hvoslef-Eide and Oomen (131)]. Because these abilities rely on suppressing older memories and inputting new associations, they likely rely on cholinergic inputs that modify hippocampal neurogenesis.

Neural stem cells in the hippocampus express ACh receptors, including $\mathrm{mAChRs}$ and $\alpha 7 \mathrm{nAChRs}$ (130), providing a possible mechanism by which the cholinergic system influences neurogenesis. In general, in vivo and in vitro studies show that cholinergic receptor stimulation increases neural stem cell proliferation (132). Activation of the $\alpha 7 \mathrm{nAChR} v i a$ increased ACh levels has been shown to enhance new neuron survival, but not differentiation or proliferation [see Kita et al. (133) and Narla et al. (134) for reviews]. These manipulations may be influencing neuronal progenitors through ACh receptors, but they also may be impacting neuronal proliferation and survival by acting on microglia. However, this possibility has not been addressed directly.

Cholinergic stimulation via increased ACh levels also promotes hippocampal neurogenesis, and decreased ACh levels impair it $(123,135)$. There is some evidence that a high-choline diet in adulthood, leading to increased ACh synthesis (136), increases proliferation and/or survival of hippocampal neurons (137). If choline-induced proliferation occurred, then it was likely due to a different mechanism than the $\alpha 7 \mathrm{nAChR}$ because of previous research implicating this receptor in neuronal survival but not proliferation [see Kita et al. (133) and Narla et al. (134) for reviews]. AChE inhibitors also upregulate proliferation of cells in the DG $(129,130,132)$ and exercise-induced proliferation of aged neural stem cells is prevented by lesions of the septal cholinergic system $(132,138)$. These findings indicate that neural stem cells respond to cholinergic stimulation even in aged animals.

As was true for memory function, the immune system is needed for neurogenesis, but overactivation leads to a decrease in neurogenesis. Mice lacking T- and B-cells have impaired hippocampal neurogenesis, which is rescued by reintroducing T-cells in the periphery (139). Because some of the reintroduced T-cells likely had the ability to make and release $\mathrm{ACh}$, it is possible that the restoration of neurogenesis was via increases in ACh. As with LTP, DG neurogenesis requires some microglia (140). However, microglial overactivation, for example following stress, infection, or disease, appears to compromise neurogenesis, which may contribute to the memory impairments seen in these conditions. When the immune system is activated by stress, minocycline decreases microglial activation and rescues adult hippocampal neurogenesis in mice (141). Minocycline also rescues neurogenesis in $\mathrm{AD}$-model and schizophrenia-model mice that have been exposed to LPS (142-144). IL-6 and TNF- $\alpha$ have been shown to decrease hippocampal neurogenesis in adulthood when overexpressed (125), providing further evidence that an increase in neuroinflammation leads to a decrease in neurogenesis.

In addition to impairing neurogenesis, inflammatory cytokine IL-6 is neurotoxic. In a study analyzing amyotrophic lateral sclerosis (ALS) blood cells, which normally secrete TNF- $\alpha$ and IL-6, researchers found that these cells were toxic to rat neurons in vitro (145). Adding an anti-IL-6 antibody blunted the toxicity, and anti-TNF- $\alpha$ and anti-IL- $1 \beta$ antibodies did so to a lesser extent. This study in particular is critical in parsing out the effects of the often-grouped-together cytokines (TNF- $\alpha$, IL-1 $\beta$, and IL-6): IL- 6 is shown to play the largest role of the three in neurotoxicity. Additionally, overexpression of IL-6 led to more neurodegeneration by several metrics (146). Inflammatory cytokines released by microglia lead to impaired neurogenesis and increased neurodegeneration. There have not been specific studies elucidating the role of microglial $\alpha 7 \mathrm{nAChRs}$ in neurogenesis, but it is possible that their activation leads to fewer inflammatory cytokines, leading to increased neurogenesis and cell survival. Together, these data suggest that cholinergic stimulation of the DG may modify hippocampal neurogenesis directly via stimulation of ACh receptors on DG stem cells or indirectly via stimulation of microglia and the subsequent inhibition of IL- 6 and TNF- $\alpha$.

\section{CLINICAL APPLICATIONS}

Inflammation and the central release of inflammatory cytokines have been proposed as a mechanism underlying cognitive decline or dysfunction in mouse models of $\mathrm{AD}$ [reviewed in Mosher and Wyss-Coray (147)], stress (148), cancer-treatment (e.g., irradiation and chemotherapy) $(149,150)$, multiple sclerosis (151), and obesity (152). The degeneration of the basal forebrain cholinergic system is a factor in many forms of dementia: not only in $\mathrm{AD}$, but also in Parkinson's disease, Down syndrome, ALS, and supranuclear palsy [see Ferreira-Vieira et al. (60)]. One likely possibility that is sometimes overlooked is that the loss of cholinergic input 
in these disorders may unmask inflammation in the hippocampus, leading to impaired cognition.

\section{Parkinson's Disease}

Parkinson's disease, while characterized by motor deficits, produces impairments in working memory, attention, and a two to six times higher risk of dementia $(153,154)$. Mouse models show decreased cortical ACh and impaired performance in hippocampal tasks such as the Y-maze, novel-object recognition, object-place recognition, and operant reversal learning (155). Activation of nAChRs, including the $\alpha 7 \mathrm{nAChR}$, is neuroprotective in animal models of Parkinson's disease [reviewed in Quik et al. (156)]. In Parkinson's patients, lower cholinergic activity, lower basal forebrain volume, and cholinergic denervation in the thalamus and cortex are all associated with impaired cognition (38, 157-159). Based on this evidence, the cholinergic deficits underlying Parkinson's disease may be causally linked to the memory deficits.

While Parkinson's disease causes a loss of dopaminergic neurons, it also impacts the cholinergic system and produces neuroinflammation. For example, in a mouse model of Parkinson's, microglia and astrocytes in the substantia nigra are increased in number and show more activation-associated morphology compared to controls (24). Microglial number, as well as astrocyte number and activation, were decreased following application of a nAChR agonist. Alpha7 nAChR activation prevents dopaminergic cell death by inhibiting the activation of both astrocytes and microglia in the substantia nigra (24). These findings suggest that Parkinson's is inherently inflammatory, and this inflammation is decreased by activating nAChRs. This inflammatory profile may be either the cause or a result of dopaminergic cell death. If $\mathrm{nAChR}$ activation, and hence activation of the cholinergic anti-inflammatory pathway in the brain, prevents dopaminergic cell death, it is possible that the inflammation itself has a role in neurodegeneration in Parkinson's. Therefore, blunting neuroinflammation by activating $\alpha 7 \mathrm{nAChRs}$ might be a promising therapy to prevent neuron loss in these patients. Though this study examines the substantia nigra, it is possible that inflammation is also occurring in the hippocampus, which would then contribute to loss of cognitive function seen in Parkinson's.

Cholinergic drugs have, in fact, been used to treat Parkinson'sassociated cognitive deficits with some success [see Pagano et al. (160) for a meta-analysis]. Interestingly, the prevalence of Parkinson's disease is decreased in smokers [see Quik et al. (161)] suggesting that nicotine may be neuroprotective, though the target of nicotine action for this beneficial effect is not yet known [see Piao et al. (162)]. It has been suggested that neuroinflammation may not just be the result of the cell loss seen in Parkinson's disease, but that noradrenergic and cholinergic hypofunction may contribute to dysregulation of neuron-glia interactions, leading to inflammation and, eventually, neurodegeneration (163). Thus, a better understanding of the role of cholinergic systems in modulating communication between glia and neurons may lead to the development of cholinergic drugs that could be promising for prevention or treatment of Parkinson's disease.

\section{Alzheimer's Disease}

Cholinergic neurons in the basal forebrain selectively degenerate in $\operatorname{AD}(36,164,165)$, and these cells are also the first neurons effected in early AD [see the following reviews $(40,166,167)]$. Impaired cognitive function in $\mathrm{AD}$ is associated with increased neurofibrillary tangle density in the basal forebrain (168). As well, postmortem brains of AD patients have lower levels of ChAT and AChE, regardless of age (169). These findings led to the "cholinergic hypothesis" for $\mathrm{AD}$ and to the treatment of $\mathrm{AD}$ patients with AChE inhibitors. The widely held view is that this drug treatment helps to negate the loss of cholinergic neurons by increasing ACh postsynaptic action. In contrast, not much work has been devoted to the effects of these drugs on glia in AD patients (170).

$\mathrm{AD}$ is also characterized by a heightened profile of neuroinflammation [see Calsolaro and Edison (171)]. AD patients have more TNF- $\alpha$ and IL- 6 in both serum and brain, indicating an inflammatory phenotype $(172,173)$, and higher levels of TNF- $\alpha$ are highly correlated with rapid cognitive decline (174). Post-mortem AD brains also have more activated microglia and astrocytes (175). Microglia in particular have been implicated in the excessive neuronal loss seen in $\mathrm{AD}$ (176) and overactivation of microglia is seen relatively early in the progression of the disease (177). Thus, AD neuropathology is characterized not only by a loss of cholinergic neurons but also by increased neuro-inflammation. Interestingly, peripheral inflammation has been linked with early-onset $\mathrm{AD}$ more so than with late-onset type $\mathrm{AD}$ (178), suggesting that inflammation may be more critical feature in the development or progression of the familial form of the disease.

As in Parkinson's disease, it is still not clear exactly how the innate immune system is involved in $\mathrm{AD}$, specifically whether it is a cause or effect of pathology. Some studies show that neuroinflammation, though contributing to an $\mathrm{AD}$ phenotype, is initiated by amyloid- $\beta$ and thus occurs as a result of $\mathrm{AD}$ neuropathogenesis. For example, microglial TNF- $\alpha$ was shown to catalyze a cascade of cellular events in vitro that characterize $\mathrm{AD}$, including cell toxicity (179). Amyloid- $\beta$ peptides also appear to activate microglia, which initiate the toxic "cell cycle events" via TNF- $\alpha$. In contrast, TNF- $\alpha$ knockout mice do not show these toxic "cell cycle events"-powerfully implicating this cytokine in the neuronal death seen in AD. Because there are $\alpha 7 \mathrm{nAChRs}$ on microglia, perhaps activation of these receptors could have a hand in preventing $\mathrm{AD}$ pathology.

It is worth mentioning that the interaction between the cholinergic and neuroimmune systems differs in $\mathrm{AD}$ versus normal aging [see Schliebs and Arendt (180)]. Specifically, cholinergic cell loss is seen in $\mathrm{AD}$, but cholinergic dysfunction (in the form of synaptic losses and other modifications) is seen in normal aging (36, 181-183).

However, the link between TNF- $\alpha$, IL- $1 \beta$, and IL- 6 and AD is not completely clear. Expression of these cytokines in blood serum is increased in early-onset AD patients, but not late-onset AD patients (178). TNF- $\alpha$ expression decreases the presence of amyloid- $\beta$ plaques in the mouse hippocampus (184), indicating that these cytokines may actually decrease AD pathology. Clearly, more research is needed into the complicated role of inflammatory cytokines in $\mathrm{AD}$ patients. 
Cholinomimetic drugs, especially AChE inhibitors, have been the first line of defense in $\mathrm{AD}$ treatment for many years, and as mentioned above, their benefits are thought to be due to a synaptic increase in ACh or direct stimulation of ACh receptors. However, some of the benefits of these drugs in $\mathrm{AD}$ patients may be due to decreases in inflammation in addition to their synaptic actions. Levels of IL-6 are higher in the brains of AD patients-however, this level decreases dose-dependently based on how many months the patients have taken AChE inhibitors (185). Possibly, by acting on microglial $\alpha 7 \mathrm{nAChRs,} \mathrm{cholinergic}$ drugs may decrease the release of inflammatory cytokines and slow neurodegeneration.

Neuroinflammation following neurodegeneration and other neuropathologies (plaques and tangles) likely contributes to clinical impairments in memory (and perhaps other symptoms as well) in both Parkinson's disease and $\mathrm{AD}$, and speeds progression of these diseases. However, it is also possible that breakdown in the innate immune system, leading to altered glial-neuron responses, contributes to the onset of $\mathrm{AD}$ and Parkinson's in different ways. Dursun et al. (178) compared peripheral cytokine levels in early-onset $\mathrm{AD}$, late-onset $\mathrm{AD}$, mild cognitive impairment, and Parkinson's disease. Though early-onset AD patients displayed increased levels of inflammatory cytokines, Parkinson's disease patients exhibited a different profile: IL- $1 \beta$ was increased, but IL-6 was significantly decreased. The interaction between these two cytokines appears to be different in AD and Parkinson's disease, suggesting that the glial contributions to these diseases may be different.

\section{REFERENCES}

1. Alzheimer A. Uber einen eigenartigen schweren Erkrankungsprozess der Hirninde. Neurologisches Centralblatt (1906) 25:1134.

2. Bartus RT, Dean RL III, Beer B, Lippa AS. The cholinergic hypothesis of geriatric memory dysfunction. Science (1982) 217:408-14. doi:10.1126/ science.7046051

3. Drachman DA, Leavitt J. Human memory and the cholinergic system: a relationship to aging? Arch Neurol (1974) 30:113-21. doi:10.1001/ archneur.1974.00490320001001

4. Ballinger EC, Ananth M, Talmage DA, Role LW. Basal forebrain cholinergic circuits and signaling in cognition and cognitive decline. Neuron (2016) 91:1199-218. doi:10.1016/j.neuron.2016.09.006

5. Achour SB, Pascual O. Glia: the many ways to modulate synaptic plasticity. Neurochem Int (2010) 57:440-5. doi:10.1016/j.neuint.2010.02.013

6. Albuquerque EX, Pereira EF, Alkondon M, Rogers SW. Mammalian nicotinic acetylcholine receptors: from structure to function. Physiol Rev (2009) 89:73-120. doi:10.1152/physrev.00015.2008

7. Dale HH. The action of certain esters and ethers of choline, and their relation to muscarine. J Pharmacol Exp Ther (1914) 6:147-90.

8. Loewi O. Über humorale übertragbarkeit der Herznervenwirkung. Pflüger's Archiv für die gesamte Physiologie des Menschen und der Tiere (1921) 189: 239-42. doi:10.1007/bf01738910

9. Wessler I, Kirkpatrick CJ. Acetylcholine beyond neurons: the nonneuronal cholinergic system in humans. Br J Pharmacol (2008) 154:1558-71. doi:10.1038/bjp.2008.185

10. Rosas-Ballina M, Olofsson PS, Ochani M, Valdés-Ferrer S, Levine YA, Reardon C, et al. Acetylcholine-synthesizing $\mathrm{T}$ cells relay neural signals in a vagus nerve circuit. Science (2011) 334:98-101. doi:10.5524/100010

11. Vijayaraghavan S, Karami A, Aeinehband S, Behbahani H, Grandien A, Nilsson B, et al. Regulated extracellular choline acetyltransferase activity-the plausible missing link of the distant action of acetylcholine in the cholinergic

\section{CONCLUSION}

Acetylcholine has multiple mechanisms by which it can modulate hippocampal memory: ACh binds directly to neuronal pre- and postsynaptic receptors, initiating downstream neuronal actions, and to receptors on astrocytes and microglia to decrease proinflammatory cytokines and increase the release of growth factors like BDNF. ACh can also act via the peripheral or central anti-inflammatory pathways by suppressing overactivation of peripheral macrophages or central microglia to indirectly aid memory. Not only does evidence point to multiple effects of ACh on memory processes, there are also multiple effects of $\mathrm{ACh}$ on neuroplasticity-specifically, alteration of spine density, synaptic strength, BDNF, and hippocampal neurogenesis. These findings suggest new ways of preventing age-related memory decline and perhaps delaying or preventing the cognitive impairments accompanying neurodegenerative disorders.

\section{AUTHOR CONTRIBUTIONS}

SVM wrote this manuscript with significant contribution in ideas, structure, and editing from CLW.

\section{ACKNOWLEDGMENTS}

The authors would like to thank Dr. Warren H. Meck, Dr. Niccolò Terrando, and Dr. Henry Yin for their helpful suggestions on the content of this manuscript.

anti-inflammatory pathway. PLoS One (2013) 8:e65936. doi:10.1371/journal. pone.0065936

12. Frakes AE, Ferraiuolo L, Haidet-Phillips AM, Schmelzer L, Braun L, Miranda CJ, et al. Microglia induce motor neuron death via the classical NF-кB pathway in amyotrophic lateral sclerosis. Neuron (2014) 81:1009-23. doi:10.1016/j.neuron.2014.01.013

13. Chan WK, Wong PTH, Sheu FS. Frontal cortical $\alpha 7$ and $\alpha 4 \beta 2$ nicotinic acetylcholine receptors in working and reference memory. Neuropharmacology (2007) 52:1641-9. doi:10.1016/j.neuropharm.2007.03.008

14. Decker MW, Sullivan J, Arneric S, Williams M. Neuronal nicotinic acetylcholine receptors: novel targets for CNS therapeutics. In: Bloom F, Kupfer D, editors. Psychopharmacology: Fourth Generation of Progress. New York: Raven Press (2000). p. 787-98.

15. Gotti C, Fornasari D, Clementi F. Human neuronal nicotinic receptors. Prog Neurobiol (1997) 53:199-237. doi:10.1016/S0301-0082(97)00034-8

16. Dineley-Miller K, Patrick J. Gene transcripts for the nicotinic acetylcholine receptor subunit, beta4, are distributed in multiple areas of the rat central nervous system. Brain Res Mol Brain Res (1992) 16:339-44. doi:10.1016/ 0169-328X(92)90244-6

17. Fabian-Fine R, Skehel P, Errington ML, Davies HA, Sher E, Stewart MG, et al. Ultrastructural distribution of the $\alpha 7$ nicotinic acetylcholine receptor subunit in rat hippocampus. J Neurosci (2001) 21:7993-8003.

18. Gahring LC, Persiyanov K, Dunn D, Weiss R, Meyer EL, Rogers SW. Mouse strain-specific nicotinic acetylcholine receptor expression by inhibitory interneurons and astrocytes in the dorsal hippocampus. J Comp Neurol (2004) 468:334-46. doi:10.1002/cne.10943

19. Gahring LC, Rogers SW. Nicotinic acetylcholine receptor expression in the hippocampus of 27 mouse strains reveals novel inhibitory circuitry. Hippocampus (2008) 18:737-49. doi:10.1002/hipo.20430

20. Kawashima K, Fujii T. The lymphocytic cholinergic system and its contribution to the regulation of immune activity. Life Sci (2003) 74:675-96. doi:10.1016/j. lfs.2003.09.037 
21. Egea J, Buendia I, Parada E, Navarro E, Leon R, Lopez MG. Anti-inflammatory role of microglial alpha7 $\mathrm{nAChRs}$ and its role in neuroprotection. Biochem Pharmacol (2015) 97:463-72. doi:10.1016/j.bcp.2015.07.032

22. Suzuki T, Hide I, Matsubara A, Hama C, Harada K, Miyano K, et al. Microglial alpha7 nicotinic acetylcholine receptors drive a phospholipase C/IP3 pathway and modulate the cell activation toward a neuroprotective role. J Neurosci Res (2006) 83:1461-70. doi:10.1002/jnr.20850

23. Shen J.-x, Yakel JL. Functional $\alpha 7$ nicotinic ACh receptors on astrocytes in rat hippocampal CA1 slices. J Mol Neurosci (2012) 48:14-21. doi:10.1007/ s12031-012-9719-3

24. Liu Y, Hu J, Wu J, Zhu C, Hui Y, Han Y, et al. $\alpha 7$ nicotinic acetylcholine receptor-mediated neuroprotection against dopaminergic neuron loss in an MPTP mouse model via inhibition of astrocyte activation. J Neuroinflammation (2012) 9:98. doi:10.1186/1742-2094-9-98

25. Wang H, Yu M, Ochani M, Amella CA, Tanovic M, Susarla S, et al. Nicotinic acetylcholine receptor alpha7 subunit is an essential regulator of inflammation. Nature (2003) 421:384-8. doi:10.1038/nature01339

26. Weathers SP, Kotagal V, Bohnen NI, Chou KL. Risky driving and pedunculopontine nucleus-thalamic cholinergic denervation in Parkinson disease. Parkinsonism Relat Disord (2014) 20:13-6. doi:10.1016/j.parkreldis. 2013.08.021

27. Martinez-Gonzalez C, Bolam J, Mena-Segovia J. Topographical organization of the pedunculopontine nucleus. Front Neuroanat (2011) 5:22. doi:10.3389/ fnana.2011.00022

28. Ye M, Hayar A, Strotman B, Garcia-Rill E. Cholinergic modulation of fast inhibitory and excitatory transmission to pedunculopontine thalamic projecting neurons. J Neurophysiol (2010) 103:2417-32. doi:10.1152/jn.01143.2009

29. Goldberg JA, Reynolds JNJ. Spontaneous firing and evoked pauses in the tonically active cholinergic interneurons of the striatum. Neuroscience (2011) 198:27-43. doi:10.1016/j.neuroscience.2011.08.067

30. Mesulam M, Mufson EJ, Levey AI, Wainer BH. Cholinergic innervation of cortex by the basal forebrain: cytochemistry and cortical connections of the septal area, diagonal band nuclei, nucleus basalis (substantia innominata), and hypothalamus in the rhesus monkey. J Comp Neurol (1983) 214:170-97. doi:10.1002/cne.902140206

31. Perez-Lloret S, Barrantes FJ. Deficits in cholinergic neurotransmission and their clinical correlates in Parkinson's disease. NPJ Parkinsons Dis (2016) 2:16001. doi:10.1038/npjparkd.2016.1

32. Woolf NJ. Cholinergic systems in mammalian brain and spinal cord. Prog Neurobiol (1991) 37:475-524. doi:10.1016/0301-0082(91)90006-M

33. Khakpai F, Nasehi M, Haeri-Rohani A, Eidi A, Zarrindast M. Septohippocampo-septal loop and memory formation. Basic Clin Neurosci (2013) 4:5-23.

34. Teles-Grilo Ruivo LM, Mellor JR. Cholinergic modulation of hippocampal network function. Front Synaptic Neurosci (2013) 5:2. doi:10.3389/fnsyn.2013. 00002

35. von Engelhardt J, Eliava M, Meyer AH, Rozov A, Monyer H. Functional characterization of intrinsic cholinergic interneurons in the cortex. J Neurosci (2007) 27:5633-42. doi:10.1523/JNEUROSCI.4647-06.2007

36. Whitehouse PJ, Price DL, Struble RG, Clark AW, Coyle JT, DeLong MR. Alzheimer's disease and senile dementia: loss of neurons in the basal forebrain. Science (1982) 215:1237-9. doi:10.1126/science.7058341

37. Himmelheber AM, Sarter M, Bruno JP. Increases in cortical acetylcholine release during sustained attention performance in rats. Brain Res Cogn Brain Res (2000) 9:313-25. doi:10.1016/S0926-6410(00)00012-4

38. Bohnen NI, Albin RL, Muller ML, Petrou M, Kotagal V, Koeppe RA, et al. Frequency of cholinergic and caudate nucleus dopaminergic deficits across the predemented cognitive spectrum of Parkinson disease and evidence of interaction effects. JAMA Neurol (2015) 72:194-200. doi:10.1001/jamaneurol. 2014.2757

39. Changeux JP, Corringer PJ, Maskos U. The nicotinic acetylcholine receptor: from molecular biology to cognition. Neuropharmacology (2015) 96:135-6. doi:10.1016/j.neuropharm.2015.03.024

40. Lombardo S, Maskos U. Role of the nicotinic acetylcholine receptor in Alzheimer's disease pathology and treatment. Neuropharmacology (2015) 96:255-62. doi:10.1016/j.neuropharm.2014.11.018

41. Paul S, Jeon WK, Bizon JL, Han JS. Interaction of basal forebrain cholinergic neurons with the glucocorticoid system in stress regulation and
cognitiveimpairment.FrontAgingNeurosci(2015)7:43.doi:10.3389/fnagi.2015. 00043

42. Smucny J, Visani A, Tregellas JR. Could vagus nerve stimulation target hippocampal hyperactivity to improve cognition in schizophrenia? Front Psychiatry (2015) 6:43. doi:10.3389/fpsyt.2015.00043

43. Pavlov VA, Tracey KJ. The cholinergic anti-inflammatory pathway. Brain Behav Immun (2005) 19:493-9. doi:10.1016/j.bbi.2005.03.015

44. Gallowitsch-Puerta M, Pavlov VA. Neuro-immune interactions via the cholinergic anti-inflammatory pathway. Life Sci (2007) 80:2325-9. doi:10.1016/ j.lfs.2007.01.002

45. De Rosa MJ, del Carmen Esandi M, Garelli A, Rayes D, Bouzat C. Relationship between $\alpha 7 \mathrm{nAChR}$ and apoptosis in human lymphocytes. J Neuroimmunol (2005) 160:154-61. doi:10.1016/j.jneuroim.2004.11.010

46. Nizri E, Hamra-Amitay Y, Sicsic C, Lavon I, Brenner T. Anti-inflammatory properties of cholinergic up-regulation: a new role for acetylcholinesterase inhibitors. Neuropharmacology (2006) 50:540-7. doi:10.1016/j.neuropharm. 2005.10.013

47. Sopori ML, Kozak W. Immunomodulatory effects of cigarette smoke. J Neuroimmunol (1998) 83:148-56. doi:10.1016/S0165-5728(97)00231-2

48. Borovikova LV, Ivanova S, Zhang M, Yang H, Botchkina GI, Watkins LR, et al. Vagus nerve stimulation attenuates the systemic inflammatory response to endotoxin. Nature (2000) 405:458-62. doi:10.1038/35013070

49. Koopman FA, Chavan SS, Miljko S, Grazio S, Sokolovic S, Schuurman PR, et al. Vagus nerve stimulation inhibits cytokine production and attenuates disease severity in rheumatoid arthritis. Proc Natl Acad Sci U S A (2016) 113:8284-9. doi:10.1073/pnas.1605635113

50. Steinberg BE, Sundman E, Terrando N, Eriksson LI, Olofsson PS. Neural control of inflammation: implications for perioperative and critical care. Anesthesiology (2016) 124:1174-89. doi:10.1097/ALN.0000000000 001083

51. Watkins LR, Goehler LE, Relton JK, Tartaglia N, Silbert L, Martin D, et al. Blockade of interleukin-1 induced hyperthermia by subdiaphragmatic vagotomy: evidence for vagal mediation of immune-brain communication. Neurosci Lett (1995) 183:27-31. doi:10.1016/0304-3940(94)11105-R

52. Tracey KJ. The inflammatory reflex. Nature (2002) 420:853-9. doi:10.1038/ nature 01321

53. De Simone R, Ajmone-Cat MA, Carnevale D, Minghetti L. Activation of alpha7 nicotinic acetylcholine receptor by nicotine selectively up-regulates cyclooxygenase- 2 and prostaglandin E2 in rat microglial cultures. J Neuroinflammation (2005) 2:4. doi:10.1186/1742-2094-2-4

54. Pavlov VA, Parrish WR, Rosas-Ballina M, Ochani M, Puerta M, Ochani K, et al. Brain acetylcholinesterase activity controls systemic cytokine levels through the cholinergic anti-inflammatory pathway. Brain Behav Immun (2009) 23:41-5. doi:10.1016/j.bbi.2008.06.011

55. Shytle RD, Mori T, Townsend K, Vendrame M, Sun N, Zeng J, et al. Cholinergic modulation of microglial activation by alpha 7 nicotinic receptors. J Neurochem (2004) 89:337-43. doi:10.1046/j.1471-4159.2004.02347.x

56. Yamada-Nomoto K, Yoshino O, Akiyama I, Ushijima A, Ono Y, Shima T, et al. Alpha-7 nicotinic acetylcholine receptor ( $\mathrm{AAChR}$ ) agonist inhibits the development of endometriosis by regulating inflammation. Am J Reprod Immunol (2016) 76:491-8. doi:10.1111/aji.12592

57. Giunta B, Ehrhart J, Townsend K, Sun N, Vendrame M, Shytle D, et al. Galantamine and nicotine have a synergistic effect on inhibition of microglial activation induced by HIV-1 gp120. Brain Res Bull (2004) 64:165-70. doi:10.1016/j.brainresbull.2004.06.008

58. Jinno S, Fleischer F, Eckel S, Schmidt V, Kosaka T. Spatial arrangement of microglia in the mouse hippocampus: a stereological study in comparison with astrocytes. Glia (2007) 55:1334-47. doi:10.1002/glia.20552

59. Hasselmo ME, Sarter M. Modes and models of forebrain cholinergic neuromodulation of cognition. Neuropsychopharmacology (2011) 36:52-73. doi:10.1038/npp.2010.104

60. Ferreira-Vieira T, Guimaraes I, Silva F, Ribeiro F. Alzheimer's disease: targeting the cholinergic system. Curr Neuropharmacol (2016) 14:101-15. doi:10.2174/1570159X13666150716165726

61. Blake MG, Boccia MM. Basal forebrain cholinergic system and memory. In: Geyer MA, Ellenbroek BA, Marsden CA, Barnes Th R E, Andersen SL, editors. Current Topics in Behavioral Neurosciences. Berlin, Heidelberg: Springer Press (2017). p. 1-21. 
62. Knox D. The role of basal forebrain cholinergic neurons in fear and extinction memory. Neurobiol Learn Mem (2016) 133:39-52. doi:10.1016/ j.nlm.2016.06.001

63. Parent MB, Baxter MG. Septohippocampal ACh: involved in but not necessary for learning and memory? Learn Mem (2004) 11:9-20. doi:10.1101/lm.69104

64. Park GA, Pappas BA, Murtha SM, Ally A. Enriched environment primes forebrain choline acetyltransferase activity to respond to learning experience. Neurosci Lett (1992) 143:259-62. doi:10.1016/0304-3940(92)90278-F

65. Baxter M, Frick K, Price D, Breckler S, Markowska A, Gorman L. Presynaptic markers of cholinergic function in the rat brain: relationship with age and cognitive status. Neuroscience (1999) 89:771-80. doi:10.1016/S03064522(98)00374-1

66. Stancampiano R, Cocco S, Cugusi C, Sarais L, Fadda F. Serotonin and acetylcholine release response in the rat hippocampus during a spatial memory task. Neuroscience (1999) 89:1135-43. doi:10.1016/S0306-4522(98)00397-2

67. Tian Q, Lin ZQ, Wang XC, Chen J, Wang Q, Gong CX, et al. Injection of okadaic acid into the meynert nucleus basalis of rat brain induces decreased acetylcholine level and spatial memory deficit. Neuroscience (2004) 126:277-84. doi:10.1016/j.neuroscience.2004.03.037

68. Herzog CD, Gandhi C, Bhattacharya P, Walsh TJ. Effects of intraseptal zolpidem and chlordiazepoxide on spatial working memory and high-affinity choline uptake in the hippocampus. Neurobiol Learn Mem (2000) 73:168-79. doi:10.1006/nlme.1999.3928

69. Decker MW, Majchrzak MJ, Anderson DJ. Effects of nicotine on spatial memory deficits in rats with septal lesions. Brain Res (1992) 572:281-5. doi:10.1016/0006-8993(92)90485-R

70. Hodges H, Allen Y, Kershaw T, Lantos P, Gray J, Sinden J. Effects of cholinergic-rich neural grafts on radial maze performance of rats after excitotoxic lesions of the forebrain cholinergic projection system-I. Amelioration of cognitive deficits by transplants into cortex and hippocampus but not into basal forebrain. Neuroscience (1991) 45:587-607.

71. Levin ED, Christopher NC, Briggs SJ, Rose JE. Chronic nicotine reverses working memory deficits caused by lesions of the fimbria or medial basalocortical projection. Brain Res Cogn Brain Res (1993) 1:137-43. doi:10.1016/ 0926-6410(93)90021-V

72. Maho C, Dutrieux G, Ammassari-Teule M. Parallel modifications of spatial memory performances, exploration patterns, and hippocampal theta rhythms in fornix-damaged rats: reversal of oxotremorine. Behav Neurosci (1988) 102:601. doi:10.1037/0735-7044.102.4.601

73. Easton A, Douchamps V, Eacott M, Lever C. A specific role for septohippocampal acetylcholine in memory? Neuropsychologia (2012) 50:3156-68. doi:10.1016/j.neuropsychologia.2012.07.022

74. Hasselmo ME. How We Remember: Brain Mechanisms of Episodic Memory. Cambridge: MIT Press (2012).

75. Baxter MG, Bucci DJ, Gorman LK, Wiley RG, Gallagher M. Selective immunotoxic lesions of basal forebrain cholinergic cells: effects on learning and memory in rats. Behav Neurosci (1995) 109:714-22. doi:10.1037/07357044.109.4.714

76. Giovannini MG, Rakovska A, Benton RS, Pazzagli M, Bianchi L, Pepeu G. Effects of novelty and habituation on acetylcholine, GABA, and glutamate release from the frontal cortex and hippocampus of freely moving rats. Neuroscience (2001) 106:43-53. doi:10.1016/S0306-4522(01)00266-4

77. Thiel CM, Huston JP, Schwarting RKW. Hippocampal acetylcholine and habituation learning. Neuroscience (1998) 85:1253-62. doi:10.1016/S03064522(98)00030-X

78. Flicker C, Geyer MA. Behavior during hippocampal microinfusions. II. Muscarinic locomotor activation. Brain Res (1982) 257:105-27. doi:10.1016/ 0165-0173(82)90007-8

79. Pabst M, Braganza O, Dannenberg H, Hu W, Pothmann L, Rosen J, et al. Astrocyte intermediaries of septal cholinergic modulation in the hippocampus. Neuron (2016) 90:853-65. doi:10.1016/j.neuron.2016.04.003

80. Hasselmo ME. The role of acetylcholine in learning and memory. Curr Opin Neurobiol (2006) 16:710-5. doi:10.1016/j.conb.2006.09.002

81. Bezzi P, Gundersen V, Galbete JL, Seifert G, Steinhauser C, Pilati E, et al. Astrocytes contain a vesicular compartment that is competent for regulated exocytosis of glutamate. Nat Neurosci (2004) 7:613-20. doi:10.1038/nn1246

82. Volterra A, Meldolesi J. Astrocytes, from brain glue to communication elements: the revolution continues. Nat Rev Neurosci (2005) 6:626-40. doi:10.1038/nrn1722
83. Lee HS, Ghetti A, Pinto-Duarte A, Wang X, Dziewczapolski G, Galimi F, et al. Astrocytes contribute to gamma oscillations and recognition memory. Proc Natl Acad Sci U S A (2014) 111:E3343-52. doi:10.1073/pnas.1410893111

84. Parkhurst CN, Yang G, Ninan I, Savas JN, Yates JR III, Lafaille JJ, et al. Microglia promote learning-dependent synapse formation through brainderived neurotrophic factor. Cell (2013) 155:1596-609. doi:10.1016/j.cell. 2013.11.030

85. Broadbent NJ, Gaskin S, Squire LR, Clark RE. Object recognition memory and the rodent hippocampus. Learn Mem (2010) 17:5-11. doi:10.1101/lm. 1650110

86. Torres L, Danver J, Ji K, Miyauchi JT, Chen D, Anderson ME, et al. Dynamic microglial modulation of spatial learning and social behavior. Brain Behav Immun (2016) 55:6-16. doi:10.1016/j.bbi.2015.09.001

87. Monk TG, Weldon BC, Garvan CW, Dede DE, Van Der Aa MT, Heilman KM, et al. Predictors of cognitive dysfunction after major noncardiac surgery. Anesthesiology (2008) 108:18-30. doi:10.1097/01.anes.0000296071.19434.1e

88. Terrando N, Eriksson LI, Ryu JK, Yang T, Monaco C, Feldmann M, et al. Resolving postoperative neuroinflammation and cognitive decline. Ann Neurol (2011) 70:986-95. doi:10.1002/ana.22664

89. Terrando N, Yang T, Ryu JK, Newton PT, Monaco C, Feldmann M, et al. Stimulation of the alpha7 nicotinic acetylcholine receptor protects against neuroinflammation after tibia fracture and endotoxemia in mice. Mol Med (2014) 20:667-75. doi:10.2119/molmed.2014.00143

90. Terrando N, Monaco C, Ma D, Foxwell BMJ, Feldmann M, Maze M. Tumor necrosis factor- $\alpha$ triggers a cytokine cascade yielding postoperative cognitive decline. Proc Natl Acad Sci U S A (2010) 107:20518-22. doi:10.1073/ pnas. 1014557107

91. Zhang M, Barde S, Yang T, Lei B, Eriksson LI, Mathew JP, et al. Orthopedic surgery modulates neuropeptides and BDNF expression at the spinal and hippocampal levels. Proc Natl Acad Sci U S A (2016) 113:E6686-95. doi:10.1073/pnas.1614017113

92. Wang H-L, Liu H, Xue Z-G, Liao Q-W, Fang H. Minocycline attenuates post-operative cognitive impairment in aged mice by inhibiting microglia activation. J Cell Mol Med (2016) 20:1632-9. doi:10.1111/jcmm.12854

93. Jang S, Dilger RN, Johnson RW. Luteolin inhibits microglia and alters hippocampal-dependent spatial working memory in aged mice. J Nutr (2010) 140:1892-8. doi:10.3945/jn.110.123273

94. Moore AH, Wu M, Shaftel SS, Graham KA, O’Banion MK. Sustained expression of interleukin-1 $\beta$ in mouse hippocampus impairs spatial memory. Neuroscience (2009) 164:1484-95. doi:10.1016/j.neuroscience.2009.08.073

95. Oitzl MS, Van Oers H, Schöbitz B, de Kloet ER. Interleukin-1 $\beta$, but not interleukin-6, impairs spatial navigation learning. Brain Res (1993) 613:160-3. doi:10.1016/0006-8993(93)90468-3

96. Barrientos RM, Higgins EA, Sprunger DB, Watkins LR, Rudy JW, Maier SF. Memory for context is impaired by a post context exposure injection of interleukin-1 beta into dorsal hippocampus. Behav Brain Res (2002) 134:291-8. doi:10.1016/s0166-4328(02)00043-8

97. Pugh CR, Fleshner M, Watkins LR, Maier SF, Rudy JW. The immune system and memory consolidation: a role for the cytokine IL-1 $\beta$. Neurosci Biobehav $\operatorname{Rev}(2001)$ 25:29-41. doi:10.1016/S0149-7634(00)00048-8

98. Williamson LL, Sholar PW, Mistry RS, Smith SH, Bilbo SD. Microglia and memory: modulation by early-life infection. J Neurosci (2011) 31:15511-21. doi:10.1523/JNEUROSCI.3688-11.2011

99. Bilbo SD, Biedenkapp JC, Der-Avakian A, Watkins LR, Rudy JW, Maier SF. Neonatal infection-induced memory impairment after lipopolysaccharide in adulthood is prevented via caspase-1 inhibition. J Neurosci (2005) 25: 8000-9. doi:10.1523/JNEUROSCI.1748-05.2005

100. Fiore M, Probert L, Kollias G, Akassoglou K, Alleva E, Aloe L. Neurobehavioral alterations in developing transgenic mice expressing TNF- $\alpha$ in the brain. Brain Behav Immun (1996) 10:126-38. doi:10.1006/brbi.1996.0013

101. Pyapali GK, Turner DA, Williams CL, Meck WH, Swartzwelder HS. Prenatal dietary choline supplementation decreases the threshold for induction of LTP in young adult rats. J Neurophysiol (1998) 79:1790-6.

102. Seol GH, Ziburkus J, Huang S, Song L, Kim IT, Takamiya K, et al. Neuromodulators control the polarity of spike-timing-dependent synaptic plasticity. Neuron (2007) 55:919-29. doi:10.1016/j.neuron.2007.08.013

103. Sugisaki E, Fukushima Y, Tsukada M, Aihara T. Cholinergic modulation on spike timing-dependent plasticity in hippocampal CA1 network. Neuroscience (2011) 192:91-101. doi:10.1016/j.neuroscience.2011.06.064 
104. Cohen AS, Raymond CR, Abraham WC. Priming of long-term potentiation induced by activation of metabotropic glutamate receptors coupled to phospholipase C. Hippocampus (1998) 8:160-70. doi:10.1002/(SICI)10981063(1998)8:2<160::AID-HIPO8>3.0.CO;2-P

105. Chen L, Yamada K, Nabeshima T, Sokabe M. $\alpha 7$ nicotinic acetylcholine receptor as a target to rescue deficit in hippocampal LTP induction in $\beta$-amyloid infused rats. Neuropharmacology (2006) 50:254-68. doi:10.1016/ j.neuropharm.2005.09.018

106. Freund RK, Graw S, Choo KS, Stevens KE, Leonard S, Dell'Acqua ML. Genetic knockout of the alpha7 nicotininc acetylcholine receptor gene alters hippocampal long-term potentiation in a background strain-dependent manner. Neurosci Lett (2016) 627:1-6. doi:10.1016/j.neulet.2016.05.043

107. Hoshino K, Hayakawa M, Morimoto Y. Minocycline prevents the impairment of hippocampal long-term potentiation in the septic mouse. Shock (2017) 48:209-21. doi:10.1097/SHK.0000000000000847

108. Gu Z, Lamb PW, Yakel JL. Cholinergic coordination of presynaptic and postsynaptic activity induces timing-dependent hippocampal synaptic plasticity. J Neurosci (2012) 32:12337-48. doi:10.1523/JNEUROSCI.2129-12.2012

109. Shen J.-x, Yakel JL. Nicotinic acetylcholine receptor-mediated calcium signaling in the nervous system. Acta Pharmacol Sin (2009) 30:673-80. doi:10.1038/aps.2009.64

110. Dummer W, Niethammer AG, Baccala R, Lawson BR, Wagner N, Reisfeld RA, et al. T-cell homeostatic proliferation elicits effective antitumor autoimmunity. J Clin Invest (2002) 110:185-92. doi:10.1172/JCI15175

111. Habbas S, Santello M, Becker D, Stubbe H, Zappia G, Liaudet N, et al. Neuroinflammatory TNF- $\alpha$ impairs memory via astrocyte signaling. Cell (2015) 163:1730-41. doi:10.1016/j.cell.2015.11.023

112. Schneider H, Pitossi F, Balschun D, Wagner A, Del Rey A, Besedovsky H. A neuromodulatory role of interleukin-1 $\beta$ in the hippocampus. Proc Natl Acad Sci U S A (1998) 95:7778-83. doi:10.1073/pnas.95.13.7778

113. Ross FM, Allan SM, Rothwell NJ, Verkhratsky A. A dual role for interleukin-1 in LTP in mouse hippocampal slices. J Neuroimmunol (2003) 144:61-7. doi:10.1016/j.jneuroim.2003.08.030

114. Czubak A, Nowakowska E, Kus K, Burda K, Metelska J, Baer-Dubowska W, et al. Influences of chronic venlafaxine, olanzapine and nicotine on the hippocampal and cortical concentrations of brain-derived neurotrophic factor (BDNF). Pharmacol Rep (2009) 61:1017-23. doi:10.1016/S17341140(09)70163-X

115. Kenny PJ, File SE, Rattray M. Acute nicotine decreases, and chronic nicotine increases the expression of brain-derived neurotrophic factor mRNA in rat hippocampus. Brain Res Mol Brain Res (2000) 85:234-8. doi:10.1016/ S0169-328X(00)00246-1

116. Turnbull MT, Coulson EJ. Cholinergic basal forebrain lesion decreases neurotrophin signaling without affecting tau hyperphosphorylation in genetically susceptible mice. J Alzheimers Dis (2017) 55:1141-54. doi:10.3233/ JAD-160805

117. Tanaka S, Ide M, Shibutani T, Ohtaki H, Numazawa S, Shioda S, et al. Lipopolysaccharide-induced microglial activation induces learning and memory deficits without neuronal cell death in rats. J Neurosci Res (2006) 83:557-66. doi:10.1002/jnr.20752

118. Barrientos R, Sprunger D, Campeau S, Higgins E, Watkins L, Rudy J, et al. Brain-derived neurotrophic factor mRNA downregulation produced by social isolation is blocked by intrahippocampal interleukin-1 receptor antagonist. Neuroscience (2003) 121:847-53. doi:10.1016/S0306-4522(03) 00564-5

119. Barrientos RM, Sprunger DB, Campeau S, Watkins LR, Rudy JW, Maier SF. BDNF mRNA expression in rat hippocampus following contextual learning is blocked by intrahippocampal IL-1 $\beta$ administration. J Neuroimmunol (2004) 155:119-26. doi:10.1016/j.jneuroim.2004.06.009

120. Barrientos RM, Frank MG, Crysdale NY, Chapman TR, Ahrendsen JT, Day HE, et al. Little exercise, big effects: reversing aging and infectioninduced memory deficits, and underlying processes. J Neurosci (2011) 31:11578-86. doi:10.1523/JNEUROSCI.2266-11.2011

121. Biggio F, Gorini G, Utzeri C, Olla P, Marrosu F, Mocchetti I, et al. Chronic vagus nerve stimulation induces neuronal plasticity in the rat hippocampus. Int J Neuropsychopharmacol (2009) 12:1209-21. doi:10.1017/ S1461145709000200

122. Fort P, Khateb A, Pegna A, Mühlethaler M, Jones BE. Noradrenergic modulation of cholinergic nucleus basalis neurons demonstrated by in vitro pharmacological and immunohistochemical evidence in the guinea-pig brain. Eur J Neurosci (1995) 7:1502-11. doi:10.1111/j.1460-9568.1995.tb01145.x

123. Jeong DU, Lee JE, Lee SE, Chang WS, Kim SJ, Chang JW. Improvements in memory after medial septum stimulation are associated with changes in hippocampal cholinergic activity and neurogenesis. Biomed Res Int (2014) 2014:568587. doi:10.1155/2014/568587

124. Meneses G, Bautista M, Florentino A, Diaz G, Acero G, Besedovsky H, et al. Electric stimulation of the vagus nerve reduced mouse neuroinflammation induced by lipopolysaccharide. J Inflamm (2016) 13:33-44. doi:10.1186/ s12950-016-0140-5

125. Monje ML, Toda H, Palmer TD. Inflammatory blockade restores adult hippocampal neurogenesis. Science (2003) 302:1760-5. doi:10.1126/science. 1088417

126. Massey KA, Zago WM, Berg DK. BDNF up-regulates $\alpha 7$ nicotinic acetylcholine receptor levels on subpopulations of hippocampal interneurons. Mol Cell Neurosci (2006) 33:381-8. doi:10.1016/j.mcn.2006.08.011

127. Freedman R, Wetmore C, Stromberg I, Leonard S, Olson L. Alphabungarotoxin binding to hippocampal interneurons: immunocytochemical characterization and effects on growth factor expression. J Neurosci (1993) 13:1965-75.

128. Cooper-Kuhn CM, Winkler J, Kuhn HG. Decreased neurogenesis after cholinergic forebrain lesion in the adult rat. J Neurosci Res (2004) 77:155-65. doi:10.1002/jnr.20116

129. Kotani S, Yamauchi T, Teramoto T, Ogura H. Donepezil, an acetylcholinesterase inhibitor, enhances adult hippocampal neurogenesis. Chem Biol Interact (2008) 175:227-30. doi:10.1016/j.cbi.2008.04.004

130. Mohapel P, Leanza G, Kokaia M, Lindvall O. Forebrain acetylcholine regulates adult hippocampal neurogenesis and learning. Neurobiol Aging (2005) 26:939-46. doi:10.1016/j.neurobiolaging.2004.07.015

131. Hvoslef-Eide M, Oomen CA. Adult neurogenesis and pattern separation in rodents: a critical evaluation of data, tasks and interpretation. Front Biol (2016) 11:168-81. doi:10.1007/s11515-016-1406-2

132. Itou Y, Nochi R, Kuribayashi H, Saito Y, Hisatsune T. Cholinergic activation of hippocampal neural stem cells in aged dentate gyrus. Hippocampus (2011) 21:446-59. doi:10.1002/hipo.20761

133. Kita Y, Ago Y, Higashino K, Asada K, Takano E, Takuma K, et al. Galantamine promotes adult hippocampal neurogenesis via M1 muscarinic and $\alpha 7$ nicotinic receptors in mice. Int J Neuropsychopharmacol (2014) 17:1957-68. doi:10.1017/S1461145714000613

134. Narla S, Klejbor I, Birkaya B, Lee Y-W, Morys J, Stachowiak EK, et al. $\alpha 7$ nicotinic receptor agonist reactivates neurogenesis in adult brain. Biochem Pharmacol (2013) 86:1099-104. doi:10.1016/j.bcp.2013.07.028

135. Paez-Gonzalez P, Asrican B, Rodriguez E, Kuo CT. Identification of distinct ChAT+ neurons and activity-dependent control of postnatal SVZ neurogenesis. Nat Neurosci (2014) 17:934-42. doi:10.1038/nn.3734

136. Cohen EL, Wurtman RJ. Brain acetylcholine: control by dietary choline. Science (1976) 191:561-2. doi:10.1126/science.1251187

137. Wong-GoodrichSJ,GlennMJ,MellottTJ,BlusztajnJK,MeckWH,WilliamsCL. Spatial memory and hippocampal plasticity are differentially sensitive to the availability of choline in adulthood as a function of choline supply in utero. Brain Res (2008) 1237:153-66. doi:10.1016/j.brainres.2008.08.074

138. Ho NF, Han SP, Dawe GS. Effect of voluntary running on adult hippocampal neurogenesis in cholinergic lesioned mice. BMC Neurosci (2009) 10:57. doi:10.1186/1471-2202-10-57

139. Ziv Y, Ron N, Butovsky O, Landa G, Sudai E, Greenberg N, et al. Immune cells contribute to the maintenance of neurogenesis and spatial learning abilities in adulthood. Nat Neurosci (2006) 9:268-75. doi:10.1038/nn1629

140. Butovsky O, Ziv Y, Schwartz A, Landa G, Talpalar AE, Pluchino S, et al. Microglia activated by IL-4 or IFN-gamma differentially induce neurogenesis and oligodendrogenesis from adult stem/progenitor cells. Mol Cell Neurosci (2006) 31:149-60. doi:10.1016/j.mcn.2005.10.006

141. McKim DB, Niraula A, Tarr AJ, Wohleb ES, Sheridan JF, Godbout JP. Neuroinflammatory dynamics underlie memory impairments after repeated social defeat. J Neurosci (2016) 36:2590-604. doi:10.1523/JNEUROSCI. 2394-15.2016

142. Biscaro B, Lindvall O, Tesco G, Ekdahl CT, Nitsch RM. Inhibition of microglial activation protects hippocampal neurogenesis and improves cognitive deficits in a transgenic mouse model for Alzheimer's disease. Neurodegener Dis (2012) 9:187-98. doi:10.1159/000330363 
143. Ekdahl CT, Claasen J-H, Bonde S, Kokaia Z, Lindvall O. Inflammation is detrimental for neurogenesis in adult brain. Proc Natl Acad Sci U S A (2003) 100:13632-7. doi:10.1073/pnas.2234031100

144. Mattei D, Djodari-Irani A, Hadar R, Pelz A, de Cossío LF, Goetz T, et al. Minocycline rescues decrease in neurogenesis, increase in microglia cytokines and deficits in sensorimotor gating in an animal model of schizophrenia. Brain Behav Immun (2014) 38:175-84. doi:10.1016/j.bbi.2014.01.019

145. Lam L, Chin L, Halder RC, Sagong B, Famenini S, Sayre J, et al. Epigenetic changes in T-cell and monocyte signatures and production of neurotoxic cytokines in ALS patients. FASEB J (2016) 30:3461-73. doi:10.1096/fj. 201600259RR

146. Heyser CJ, Masliah E, Samimi A, Campbell IL, Gold LH. Progressive decline in avoidance learning paralleled by inflammatory neurodegeneration in transgenic mice expressing interleukin 6 in the brain. Proc Natl Acad Sci U S A (1997) 94:1500-5. doi:10.1073/pnas.94.4.1500

147. Mosher KI, Wyss-Coray T. Microglial dysfunction in brain aging and Alzheimer's disease. Biochem Pharmacol (2014) 88:594-604. doi:10.1016/ j.bcp.2014.01.008

148. Ohgidani M, Kato TA, Sagata N, Hayakawa K, Shimokawa N, Sato-Kasai M, et al. TNF- $\alpha$ from hippocampal microglia induces working memory deficits by acute stress in mice. Brain Behav Immun (2016) 55:17-24. doi:10.1016/ j.bbi.2015.08.022

149. Acharya MM, Green KN, Allen BD, Najafi AR, Syage A, Minasyan H, et al. Elimination of microglia improves cognitive function following cranial irradiation. Sci Rep (2016) 6:315-45. doi:10.1038/srep31545

150. Jenrow KA, Brown SL, Lapanowski K, Naei H, Kolozsvary A, Kim JH. Selective inhibition of microglia-mediated neuroinflammation mitigates radiation-induced cognitive impairment. Radiat Res (2013) 179:549-56. doi:10.1667/rr3026.1

151. Di Filippo M, de Iure A, Giampa C, Chiasserini D, Tozzi A, Orvietani PL, et al. Persistent activation of microglia and NADPH oxidase drive hippocampal dysfunction in experimental multiple sclerosis. Sci Rep (2016) 6:209-26. doi:10.1038/srep20926

152. Bocarsly ME, Fasolino M, Kane GA, LaMarca EA, Kirschen GW, Karatsoreos IN, et al. Obesity diminishes synaptic markers, alters microglial morphology, and impairs cognitive function. Proc Natl Acad Sci U S A (2015) 112:15731-6. doi:10.1073/pnas.1511593112

153. Caballol N, Martí MJ, Tolosa E. Cognitive dysfunction and dementia in Parkinson disease. Mov Disord (2007) 22:S358-66. doi:10.1002/mds.21677

154. Jankovic J. Parkinson's disease: clinical features and diagnosis. JNeurol Neurosurg Psychiatry (2008) 79:368-76. doi:10.1136/jnnp.2007.131045

155. Magen I, Fleming SM, Zhu C, Garcia EC, Cardiff KM, Dinh D, et al. Cognitive deficits in a mouse model of pre-manifest Parkinson's disease. Eur J Neurosci (2012) 35:870-82. doi:10.1111/j.1460-9568.2012.08012.x

156. Quik M, Perez XA, Bordia T. Nicotine as a potential neuroprotective agent for Parkinson's disease. Mov Disord (2012) 27:947-57. doi:10.1002/mds. 25028

157. Bohnen NI, Muller ML, Kotagal V, Koeppe RA, Kilbourn MR, Gilman S, et al. Heterogeneity of cholinergic denervation in Parkinson's disease without dementia. J Cereb Blood Flow Metab (2012) 32:1609-17. doi:10.1038/ jcbfm.2012.60

158. Choi SH, Jung TM, Lee JE, Lee S, Sohn YH, Lee PH. Volumetric analysis of the substantia innominata in patients with Parkinson's disease according to cognitive status. Neurobiol Aging (2012) 33:1265-72. doi:10.1016/j. neurobiolaging.2010.11.015

159. Müller MLTM, Bohnen NI, Kotagal V, Scott PJH, Koeppe RA, Frey KA, et al. Clinical markers for identifying cholinergic deficits in Parkinson's disease. Mov Disord (2015) 30:269-73. doi:10.1002/mds.26061

160. Pagano G, Rengo G, Pasqualetti G, Femminella GD, Monzani F, Ferrara N, et al. Cholinesterase inhibitors for Parkinson's disease: a systematic review and meta-analysis. JNeurol Neurosurg Psychiatry (2015) 86:767-73. doi:10.1136/jnnp-2014-308764

161. Quik M, Bordia T, Huang L, Perez X. Targeting nicotinic receptors for Parkinson's disease therapy. CNS Neurol Disord Drug Targets (2011) 10:651-8. doi:10.2174/187152711797247849

162. Piao WH, Campagnolo D, Dayao C, Lukas RJ, Wu J, Shi FD. Nicotine and inflammatory neurological disorders. Acta Pharmacol Sin (2009) 30:715-22. doi:10.1038/aps.2009.67
163. Carnevale D, De Simone R, Minghetti L. Microglia-neuron interaction in inflammatory and degenerative diseases: role of cholinergic and noradrenergic systems. CNS Neurol Disord Drug Targets (2007) 6:388-97. doi:10.1186/1750-1326-6-16

164. Coyle JT, Price DL, DeLong MR. Alzheimer's disease: a disorder of cortical cholinergic innervation. Science (1983) 219:1184-90. doi:10.1126/ science.6338589

165. Muir JL. Acetylcholine, aging, and Alzheimer's disease. Pharmacol Biochem Behav (1997) 56:687-96. doi:10.1016/S0091-3057(96)00431-5

166. Craig LA, Hong NS, McDonald RJ. Revisiting the cholinergic hypothesis in the development of Alzheimer's disease. Neurosci Biobehav Rev (2011) 35:1397-409. doi:10.1016/j.neubiorev.2011.03.001

167. Mufson EJ, Counts SE, Perez SE, Ginsberg SD. Cholinergic system during the progression of Alzheimer's disease: therapeutic implications. Expert Rev Neurother (2008) 8:1703-18. doi:10.1586/14737175.8.11.1703

168. Berg L, McKeel DW, Miller JP, Baty J, Morris JC. Neuropathological indexes of Alzheimer's disease in demented and nondemented persons aged 80 years and older. Arch Neurol (1993) 50:349-58. doi:10.1001/archneur.1993. 00540040011008

169. Bierer LM, Haroutunian V, Gabriel S, Knott PJ, Carlin LS, Purohit DP, et al. Neurochemical correlates of dementia severity in Alzheimer's disease: relative importance of the cholinergic deficits. JNeurochem (1995) 64: 749-60. doi:10.1046/j.1471-4159.1995.64020749.x

170. Anand P, Singh B. A review on cholinesterase inhibitors for Alzheimer's disease. Arch Pharm Res (2013) 36:375-99. doi:10.1007/s12272-013-0036-3

171. Calsolaro V, Edison P. Neuroinflammation in Alzheimer's disease: current evidence and future directions. Alzheimers Dement (2016) 12:719-32. doi:10.1016/j.jalz.2016.02.010

172. Fillit H, Ding W, Buee L, Kalman J, Altstiel L, Lawlor B, et al. Elevated circulating tumor necrosis factor levels in Alzheimer's disease. Neurosci Lett (1991) 129:318-20. doi:10.1016/0304-3940(91)90490-K

173. Strauss S, Bauer J, Ganter U, Jonas U, Berger M, Volk B. Detection of interleukin-6 and alpha 2-macroglobulin immunoreactivity in cortex and hippocampus of Alzheimer's disease patients. Lab Invest (1992) 66:223-30.

174. Holmes C, Cunningham C, Zotova E, Woolford J, Dean C, Kerr SU, et al. Systemic inflammation and disease progression in Alzheimer disease. Neurology (2009) 73:768-74. doi:10.1212/WNL.0b013e3181b6bb95

175. Sastre M, Klockgether T, Heneka MT. Contribution of inflammatory processes to Alzheimer's disease: molecular mechanisms. Int J Dev Neurosci (2006) 24:167-76. doi:10.1016/j.ijdevneu.2005.11.014

176. Varnum MM, Ikezu T. The classification of microglial activation phenotypes on neurodegeneration and regeneration in Alzheimer's disease brain. Arch Immunol Ther Exp (Warsz) (2012) 60:251-66. doi:10.1007/s00005-0120181-2

177. Fan Z, Aman Y, Ahmed I, Chetelat G, Landeau B, Chaudhuri KR, et al. Influence of microglial activation on neuronal function in Alzheimer's and Parkinson's disease dementia. Alzheimers Dement (2015) 11:608-21. doi:10.1016/j.jalz.2014.06.016

178. Dursun E, Gezen-Ak D, Hanağası H, Bilgiç B, Lohmann E, Ertan S, et al. The interleukin 1 alpha, interleukin 1 beta, interleukin 6 and alpha-2macroglobulin serum levels in patients with early or late onset Alzheimer's disease, mild cognitive impairment or Parkinson's disease. J Neuroimmunol (2015) 283:50-7. doi:10.1016/j.jneuroim.2015.04.014

179. Bhaskar K, Maphis N, Xu G, Varvel NH, Kokiko-Cochran ON, Weick JP, et al. Microglial derived tumor necrosis factor-alpha drives Alzheimer's disease-related neuronal cell cycle events. Neurobiol Dis (2014) 62:273-85. doi:10.1016/j.nbd.2013.10.007

180. Schliebs R, Arendt T. The cholinergic system in aging and neuronal degeneration. Behav Brain Res (2011) 221:555-63. doi:10.1016/j.bbr.2010. 11.058

181. Rapp PR, Gallagher M. Preserved neuron number in the hippocampus of aged rats with spatial learning deficits. Proc Natl Acad Sci U S A (1996) 93:9926-30. doi:10.1073/pnas.93.18.9926

182. Rasmussen T, Schliemann T, Sørensen JC, Zimmer J, West MJ. Memory impaired aged rats: no loss of principal hippocampal and subicular neurons. Neurobiol Aging (1996) 17:143-7. doi:10.1016/0197-4580(95) 02032-2 
183. Ypsilanti AR, Girao da Cruz MT, Burgess A, Aubert I. The length of hippocampal cholinergic fibres is reduced in the aging brain. Neurobiol Aging (2008) 29:1666-79. doi:10.1016/j.neurobiolaging.2007.04.001

184. Chakrabarty P, Jansen-West K, Beccard A, Ceballos-Diaz C, Levites Y, Verbeeck C, et al. Massive gliosis induced by interleukin- 6 suppresses $A \beta$ deposition in vivo: evidence against inflammation as a driving force for amyloid deposition. FASEB J (2010) 24:548-59. doi:10.1096/fj.09-141754

185. RealeM,IarloriC, Gambi F,LucciI,Salvatore M, GambiD. Acetylcholinesterase inhibitors effects on oncostatin- $\mathrm{M}$, interleukin- $1 \beta$ and interleukin-6 release from lymphocytes of Alzheimer's disease patients. Exp Gerontol (2005) 40:165-71. doi:10.1016/j.exger.2004.12.003
Conflict of Interest Statement: The authors declare that the research was conducted in the absence of any commercial or financial relationships that could be construed as a potential conflict of interest.

Copyright (c) 2017 Maurer and Williams. This is an open-access article distributed under the terms of the Creative Commons Attribution License (CC BY). The use, distribution or reproduction in other forums is permitted, provided the original author(s) or licensor are credited and that the original publication in this journal is cited, in accordance with accepted academic practice. No use, distribution or reproduction is permitted which does not comply with these terms. 